\title{
a trajetória da família pinto de miranda pelo império português: ascensão econômica e social (segunda metade do século xviii) the trajectory of the pinto de miranda family in the portuguese empire: economic and social rise (second half of the $18^{\text {th }}$ century)
}

\begin{abstract}
Alexandra Maria Pereira $\star \star$
Faculdade de Economia, Administração e Contabilidade, Universidade de São Paulo, São Paulo, São Paulo, Brasil
\end{abstract}

RESUMO

$\mathrm{O}$ artigo analisa a história de vida dos irmãos Antônio Pinto de Miranda e Baltazar Pinto de Miranda,importantes homens de negócios do Império português durante a segunda metade do século XVIII. A ênfase de nossa pesquisa se voltou para o levantamento de documentação primária que permitiu avaliar tanto o processo como os elementos que nortearam a ascensão econômica e social de nossos personagens à elite mercantil portuguesa. Nesse sentido, estratégias como diversificação das atividades mercantis, participação em contratos régios, funções em cargos administrativos e aquisição de insígnias foram importantes para conferir poder econômico e distinção social. À luz dessas informações, apreendemos nas trajetórias percorridas o entrelaçamento de algumas das transformações ocorridas em um momento de transição política e econômica crucial para o Estado português.

Palavras-chave: Império português. América Portuguesa. Homens de negócio. Comércio. Prosopografia.

\section{Abstract}

The article analyses the life story of the brothers Antônio Pinto de Miranda and Baltazar Pinto de Miranda, important businessmen of the Portuguese Empire during the second half of the eighteenth century.The emphasis of our research turned to the survey of primary documentation that allowed us to evaluate both the process and the elements that guided the economic and social rise of our characters to the Portuguese merchant elite. In this sense, strategies such as diversification of commercial activities, participation in royal contracts, functions in administrative positions and acquisition of insignia were important to confer economic power and social distinction. In the light of this information, we learn from the trajectories travelled the intertwining of some of the transformations that occurred in a moment of crucial political and economic transition to the Portuguese State.

Keywords: Portuguese Empire. Portuguese America.Businessmen.Trade. Prosopography.

* O artigo é parte do relatório científico de uma pesquisa de pós-doutorado desenvolvida no Programa de Pós-Graduação em Economia da Faculdade de Economia,Administração e Contabilidade da Universidade de São Paulo.Agradeço ao supervisor da pesquisa, o professor doutor Nelson Hideiki Nozoe, pela leitura e pelas sugestões. Submetido: 19 de junho de 2019; aceito: 20 de outubro de 2019.

$\star \star$ Professora do ensino médio da rede estadual de Minas Gerais e dos cursos de graduação e pós-graduação da Faculdade Cidade de João Pinheiro e da Faculdade Patos de Minas.Pós-doutora pela Faculdade de Economia,Administração e Contabilidade, 


\section{Introdução}

As motivações econômicas de Portugal no alvorecer do século XVIII reuniram condições para o fortalecimento das atividades mercantis e, consequentemente, da sua comunidade de negociantes (Costa, 2002). Nas razões que suscitaram esse crescimento econômico estavam o surto ocasionado com a produção e o comércio de vinhos, entre os anos de 1690 e 1705, e a expansão do comércio estabelecido com suas colônias, sobretudo pela atividade comercial com o Brasil, por sua prosperidade tencionada com a exploração de ouro e posteriormente de diamantes ${ }^{1}$. Os ventos que trouxeram a bonança para Portugal setecentista foram também responsáveis pelas novas forças sociais e políticas do período, como bem destacou Vitorino Magalhães Godinho (1953, p. 79).

A historiografia já salientou que um dos desdobramentos do comércio ultramarino português articulado ao surto de exploração mineratória da colônia brasileira consistiu no fortalecimento de sua comunidade mercantil, que, na segunda metade da centúria setecentista, consolidou-se sob os auspícios da política pombalina numa burguesia mercantil portuguesa, fortemente envolvida com os monopólios e a arrecadação de tributos régios (Pedreira, 1995).

Ao analisar a trajetória do homem de negócios português Francisco Pinheiro, por exemplo, o historiador William Donovan destacou que as primeiras décadas do Setecentos foram propícias para a inserção de comerciantes dos mais variados estratos e localidades na substanciosa praça mercantil de Lisboa, pois a época, marcada pela harmonia entre as relações de seus comerciantes com os estrangeiros, constituiu-se em uma notável economia aberta a novos talentos empresariais (Donovan, 1990, p. 87).

Mesmo com o propalado fortalecimento da comunidade mercantil durante a primeira metade do século XVIII, os negociantes portugueses não se constituíram enquanto grupo coeso, assim como não desfrutavam de uma efetiva abertura política no reinado de D.JoãoV. Como exemplo

Universidade de São Paulo. Doutora em História Econômica pela Universidade de São Paulo. E-mail: alexandramaria@usp.br

1 Sobre as motivações econômicas de Portugal na primeira metade do século XVIII, ver, entre outros, os trabalhos de Costa (2006), Godinho (1953), Macedo (1992), Pedreira (1995). 
disso, Donovan ressaltou que os homens do comércio não atuaram em órgãos de poder local, sendo também a Mesa do Bem Comum dos Mercadores ligada à Confraria do Espírito Santo da Pedreira considerada de pouca eficácia (Donovan, 1990, p. 101).

Sem uma corporação de fôlego, com pouca expressividade nos assuntos relacionados à vida econômico-social da metrópole, os negociantes da primeira metade do século XVIII, como Francisco Pinheiro, foram compelidos a desenvolver individualmente um alto grau de habilidade social e política. Uma situação que, por conseguinte, gerava complexas relações clientelistas, quase sempre interdependentes entre os membros da esfera mercantil e interligadas de forma direta ao poder do monarca, D. João V (Donovan, 1990, p. 102) ${ }^{2}$.

Essa elite comercial estava disposta em cadeias mercantis geográficas que se conectavam a fim de articular os seus negócios (o comércio em grosso e os contratos régios), mas fortemente vinculada a um eixo mercantil central, a praça de Lisboa. Uma estrutura, ao que parece, relacionada à relevância da capital lusitana, como principal entreposto do comércio de abastecimento colonial, e das medidas implementadas pela Coroa em relação à associação dos negociantes ao Estado nas últimas décadas de governo de $\mathrm{D}$. João $\mathrm{V}$, mas que chegou ao seu ápice no reinado de seu sucessor, D. José I, sob a égide do primeiro-ministro Sebastião José de Carvalho e Melo³.

2 Para Leonor Freire Costa, a política pombalina estabelecida durante a segunda metade do século XVIII, voltada para uma reforma na organização mercantil, consubstanciou um "ethos mercantil" que depurou o grupo dos negociantes, forjando, dessa forma, a formação da burguesia mercantil portuguesa (Costa, 2006, p. 129). Antes disso, verificou-se que "o elevado grau de integração das redes imprimia coerência às suas estratégias, a mais das vezes direccionadas para as áreas da economia administrada, para o monopólio ou para os circuitos onde a rentabilidade dos capitais se escudava na protecção pública. Na acessibilidade à corte, aos paços do conselho da Fazenda, nas relações pessoais com membros do aparelho de Estado, em suma, na inserção num mesmo espaço social, forjava-se a identidade de certos segmentos do grupo socio-profissional e acentuava-se a sua distância relativamente a outras fracções, deste modo marginalizadas dos centros de decisão política" (Costa, 2002, p. 107). A esse respeito, ver também Macedo (1989), Monteiro (2008).

3 Jorge Borges de Macedo, em seu estudo sobre a situação econômica de Portugal no tempo de Pombal, destacou:"No campo do reforço do Estado, a atividade pombalina não foi renovadora, utilizando os organismos tradicionais assim como os métodos, ao tempo, tradicionais da monarquia portuguesa. Reorganização em Pombal quer simplesmente dizer reforço da organização existente" (Macedo, 1989, p. 47). 
Diante do exposto, este artigo propõe uma análise da família Luízes de Santa Marinha do Zêzere (como ficaram conhecidos à época), posto que influiu diretamente no lançamento de jovens portugueses da porção Norte de Portugal ao universo mercantil voltado para o abastecimento da América Portuguesa. Nomeadamente nossa investigação discorreu sobre a história de vida da família Pinto de Miranda, com destaque para os irmãos Antônio Pinto de Miranda e Baltazar Pinto de Miranda. Ambos foram membros destacados da família Luízes, com ascensão econômica e social no universo dos homens de negócios do Império português e forte atuação no comércio de abastecimento das zonas de mineração da América Portuguesa, especialmente durante o período pombalino.

\section{Os Luízes de Santa Marinha do Zêzere}

Os primeiros membros da família Luízes de que se tem notícia que se aventuraram pelo ultramar em busca de fortuna foram João da Costa Resende e Francisco Ribeiro da Fonseca. É bem provável que ambos chegaram à região na primeira década da centúria setecentista, pois Francisco Ribeiro da Fonseca, em 1720, já havia regressado para Santa Marinha do Zêzere, sua terra natal, onde passou a viver com a esposa e os filhos em uma quinta localizada em Míguas, com os rendimentos do cabedal adquirido durante os anos de atuação no comércio colonial ${ }^{4}$. Resende e Fonseca eram sobrinhos de Francisco Luiz Pinto, o pai de Manuel Cardoso Pinto e Manuel de Miranda Fraga, que, por sua vez, tiveram seus filhos inicialmente engajados no comércio de abastecimento das zonas de mineração da América Portuguesa.

A família Luízes espalhada por Santa Marinha do Zêzere descende de forma direta de Francisco Luiz Pinto. Francisco era casado com Ana Miranda, exerceu o oficio de tanoeiro e desempenhou funções que lhe conferiam notoriedade dentro do concelho de Baião, onde estava situada essa freguesia, como as de escrivão do Juízo de Órfãos, meirinho, inquiridor e juiz ${ }^{5}$. Alguns de seus descendentes migraram para o Brasil

\footnotetext{
4 IANTT, Habilitação do Santo Ofício, maço 44, doc. 911.

5 Essas informações foram retiradas do processo de familiar do Santo Ofício de seu
} 
durante a primeira metade do século XVIII. Ao todo, sete netos, dos quais três eram filhos de Manoel Cardoso Pinto e quatro de Manoel de Miranda Fraga.

Manoel Cardoso Pinto provavelmente seria o filho mais velho de Francisco, sendo também natural, fruto de um relacionamento com uma mulher solteira chamada Maria Cardosa. Manoel casou-se pela primeira vez no ano de 1705 com Josefa Pinta, de cujo matrimônio nasceu seis filhos. Em Santa Marinha ele viveu como marinheiro e arrais no rio Douro, mudando algum tempo depois com os filhos para a cidade do Porto, onde foi taberneiro e rendeiro. Casou-se pela segunda vez com uma prima chamada Maria de Távora Ferreira. Quanto aos seus filhos, Ana e Josefa viveram como religiosas de São Domingos no Convento de Corpus Christi emVila Nova de Gaia; Cosme Cardoso, o filho mais velho, foi um religioso do Convento de Santo Antônio na cidade do Rio de Janeiro; enquanto Jorge, Manoel e Antônio estiveram, por certo tempo, na colônia brasileira envolvidos com a atividade mercantil da região mineradora, regressando posteriormente para a metrópole lusa, onde viveram os últimos anos de vida, em Lisboa, como homens de negócio.

De outra parte, Manoel de Miranda Fraga era filho legítimo de Francisco Luiz Pinto, nascido do seu matrimônio com Ana Miranda. Em Santa Marinha, assim como seu pai, Fraga trabalhava como tanoeiro e exerceu o ofício de escrivão do Juízo de Órfãos do concelho de Baião. Embora não tenha sido possível precisar o número exato de filhos desse casal, dentre eles estavam cinco homens, Manoel de Miranda Fraga,João, Antônio, Baltazar e Bernardo Pinto de Miranda, além de duas mulheres, Teresa e Joana, que, até o ano de 1765, viviam com seus pais em Santa Marinha do Zêzere.

O percurso dos netos de Francisco Luiz Pinto no ultramar começou quando Jorge Pinto de Azeredo e seu irmão Manoel Cardoso Pinto fizeram a travessia para a colônia portuguesa da América, nos primeiros anos da década de 1720. Foram, inicialmente, instruídos pelos primos de seus pais, João da Costa Resende e Francisco Ribeiro da Fonseca, que, na altura, já desfrutavam de largo conhecimento sobre o comércio

neto Antônio Pinto de Miranda. IANTT, Habilitação do Santo Ofício, maço 136, doc. 2.257. 
articulado nas zonas de mineração. Nesse contexto de relações familiares, Jorge e Manoel receberam o amparo de João da Costa Resende e iniciaram suas atividades como caixeiros em sua loja localizada em Itaubira (Itabirito), na comarca deVila Rica. Na década seguinte, de 1730, o irmão mais novo, Antônio Pinto de Távora, também já se encontrava envolvido com o próspero comércio daquela região (Pereira, 2017).

Depois dos filhos de Manoel Cardoso Pinto, era a vez de os filhos de Manoel de Miranda Fraga embarcarem para o Brasil. Os primeiros a chegarem à colônia, no início do decênio de 1730, foram Manoel de Miranda Fraga e João Pinto de Miranda, que se instalaram imediatamente emVila Rica. Iniciaram na lida mercantil como caixeiros de uma loja de grande porte que seus primos Jorge e Manoel haviam estabelecido naquela vila. Em 1739, seguindo os mesmos rumos dos irmãos e primos, Antônio Pinto de Miranda e Baltazar Pinto de Miranda partiram para o Brasil, fixando residência no Rio de Janeiro, onde estabeleceram uma casa de comércio especialmente voltada para o abastecimento da capitania de Minas Gerais (Pereira, 2017).

Com esse processo de migração familiar, fica-nos a certeza de que a passagem pelo Brasil foi, efetivamente, uma oportunidade explorada pelos Luízes de Santa Marinha do Zêzere. Assim como a vida que levavam na região e a sua relação com o comércio de vinhos às margens do rio Douro, estas também foram elementos importantes para compreender o sucesso das trajetórias mercantis dos membros da família. O tino comercial e o cuidado com a alfabetização, nesse sentido, favoreceram aqueles que se aventuraram pelo ultramar e se serviram, especialmente, do comércio alentado pelos descobertos auríferos da colônia portuguesa na América, desde o alvorecer do século XVIII.

\section{A trajetória de Antônio Pinto de Miranda}

Antônio Pinto de Miranda nasceu em 1712, no lugar das Lages, que pertence ao pequeno vilarejo de Santa Marinha do Zêzere, no concelho de Baião e Bispado do Porto. Filho legítimo de Manoel de Miranda Fraga e de sua esposa Úrsula Pinta,Antônio, quando criança, frequentou a escola e algum tempo depois passou ao estudo de gramática, como era o costume entre os filhos dos principais lavradores daquela região. 
De lá partiu ainda jovem para a cidade do Porto, iniciando suas atividades no trato mercantil como caixeiro de uma casa comercial que pertenceu ao hamburguês Diogo Berquenhout ${ }^{6 .}$

Nos meados da década de 1730, atuava como consignatário de fazendas que encaminhava para o Porto do Rio de Janeiro, a fim de abastecer o comércio fomentado pela mineração. Em 1739, Antônio Pinto de Miranda mudou-se para o Rio de Janeiro em companhia de seu irmão Baltazar Pinto de Miranda, e por lá estabeleceram uma loja voltada para o abastecimento dos núcleos de mineração.A fim de reforçar o comércio com a aludida região, logo endereçava uma carta para o primo Jorge Pinto de Azeredo, homem de negócios em Minas Gerais, noticiando a sua viagem e a chegada ao Rio de Janeiro. Solicitou, na mesma carta, a esse seu primo recomendações sobre a sua casa de comércio a compradores conhecidos, "que paguem a contado" (Santos, 1994, p. 149).

Antônio, ao longo dos anos que atuou na praça mercantil do Rio de Janeiro, manteve uma assídua correspondência com comerciantes, amigos e parentes da metrópole, especialmente na cidade do Porto, de onde, ao que parece, eram encaminhadas as principais mercadorias comercializadas por ele na América Portuguesa. O exame dessa correspondência tornou-se o foco principal para que Eugênio dos Santos constituísse a sua análise sobre os irmãos Pinto de Miranda. Esse conjunto de correspondências colocou em evidência os laços de amizade e de relações comerciais que Antônio manteve, ao longo de 30 anos, com importantes comerciantes da cidade do Porto, como Diogo Berquenhout, seu antigo patrão, e Henrique Soltau (Santos, 1994, p. 150).

Algum tempo depois de se estabelecer no Rio de Janeiro, Antônio Pinto de Miranda levou sua esposa, Maria Pinta, e seus filhos para a sua companhia ${ }^{7}$. Antônio era pai de três filhos: José, Antônio e Ana Evangelista. José trabalhava com o pai, mas esteve em companhia do seu tio Baltazar em Lisboa por algum tempo, enquanto Antônio foi encaminhado para a África pelo pai, com uma carregação de mercadorias, onde até o ano de 1765 ainda permanecia, em Moçambique, atuando provavelmente no comércio de escravos (Santos, 1994, p. 152). Ana Evangelista,

6 IANTT, Habilitação da Ordem de Cristo, letra A, maço 29, doc. 2.

7 IANTT, Habilitação da Ordem de Cristo, letra A, maço 29, doc. 2. 
por sua vez, casou-se com o negociante e familiar do Santo Ofício, Domingos de Paiva Arouca ${ }^{8}$.

Por aproximadamente 15 anos, Antônio Pinto de Miranda e seu irmão Baltazar Pinto de Miranda atuaram diretamente no comércio de abastecimento das zonas de mineração, mediante uma casa comercial estabelecida no Rio de Janeiro. Com a prosperidade dos negócios, firmaram uma sociedade mercantil que, assim como tantas outras, culminou no regresso de um dos sócios para a metrópole, a fim de atuar na praça mercantil de Lisboa. Dessa forma, Baltazar, por volta de 1755, regressava para o reino? .

Assim como Eugênio dos Santos, nossa investigação permitiu partilhar da premissa de que o período de atuação em conjunto, no Rio de Janeiro, foi uma fase de prosperidade e de crescimento econômico para os irmãos Pinto de Miranda. Em boa medida, essa fase estava inserida em um contexto maior, o de prosperidade econômica das zonas de mineração da América Portuguesa. Por sua vez, durante as duas décadas iniciais da segunda metade do século XVIII, época de forte atuação mercantil dos irmãos Pinto de Miranda, iniciou-se um período marcado por novos arranjos e políticas no Império português, que influenciou diretamente a relação do Estado com a burguesia mercantil portuguesa (Guimarães; Pesavento, 2013).

Em 1748, encontramos Antônio Pinto de Miranda ao solicitar a sua habilitação no cargo de familiar do Santo Ofício, residindo na cidade do Rio de Janeiro com a esposa e filhos ${ }^{10}$. $\mathrm{Na}$ ocasião, apresentou-se como filho legítimo de Manoel de Miranda Fraga e Úrsula Pinta, e casado, na cidade do Porto, com D. Maria Pinta. Na época, ostentava a patente de capitão de Ordenança, conferindo-lhe prestígio e distinção social naquela cidade ${ }^{11}$. A escolha do seu procurador na corte para os

\footnotetext{
8 IANTT, Habilitação do Santo Ofício, maço 136, doc. 2.257.

9 IANTT, Habilitação da Ordem de Cristo, letra B, maço 3, doc. 15.

10 IANTT, Habilitação do Santo Ofício, maço 136, doc. 2.257.

11 Sua trajetória de ascensão social enquadra-se no modelo descrito por Maria Beatriz Nizza da Silva, isto é,"a estratégia nobiliárquica dos coloniais consistiu em apostar em várias pedras do xadrez das mercês régias. Muitos procuravam aliar o foro de fidalgo da Casa Real ao hábito de uma das ordens militares, ou a um posto no oficialato das milícias, ou à familiatura do Santo Ofício. Cargos camarários reconheciam a nobreza das cidades e vilas e os vários ofícios da Fazenda ou da Justiça não só asseguravam proventos aos seus proprietários como nobilitavam quem os ocupava" (Silva, 2005, p. 10).
} 
assuntos envolvendo o processo de habilitação também demonstra que Antônio já circulava entre as principais redes de negociantes do Império português do período, pois nomeou José Ferreira da Veiga um dos cem homens de negócios mais importantes da praça lisboeta, durante a governação pombalina (Pedreira, 1995, p. 165).

Das primeiras informações que chegaram aos deputados do Conselho Geral a respeito da vida pregressa do candidato, estava a afirmação de que, pela parte de seu avô paterno, Francisco Luiz, apesar de ter sido considerado legítimo cristão velho, corria rumores de descendência judaica. Uma fama proveniente de Eva Luiz, cristã nova que saiu de Lamego para viver em Gestaçô, deixando uma sucessão numerosa, mas que, apesar de muito conhecida, era fama reputada por falsa pelas sentenças ordinárias e do Santo Ofício realizadas ao longo dos anos na família dos Luízes $^{12}$.

Essa delação, amparada pelos rumores das testemunhas e pelas diligências que embaraçaram o processo de habilitação de seu primo Jorge Pinto de Azeredo, no decênio de 1740, fez com que o processo de Antônio se estendesse por 12 anos, ou seja, até 1760.A demora compeliu-o a encaminhar uma petição endereçada ao Exmo. Senhor Cardeal da Cunha, inquisidor-geral, "para haver de o criar familiar do Santo Ofício" porque "até o presente não alcançou, talvez por falta de notícia de seus avós”, argumentando ainda que sua filha, Ana Evangelista, tinha sido aprovada para se casar com o familiar Domingos de Paiva Arouca ${ }^{13}$.

Quanto às provanças sobre a sua capacidade de servir ao Santo Ofício, realizadas no Rio de Janeiro, as testemunhas concordavam que o capitão da Ordenança, Antônio Pinto de Miranda, e sua mulher, Maria Pinta, moravam naquela cidade e se tratavam à lei da nobreza, exercendo o postulante atividades no ramo mercantil com um cabedal estimado em 30.000 cruzados. Em março de 1760, para coroar a sua ascensão econômica e social como destacado negociante da praça mercantil do Rio de Janeiro,Antônio foi habilitado para o cargo de familiar do Santo Ofício ${ }^{14}$.

Vejamos adiante algumas informações que jogam luz aos negócios e à atuação de Antônio Pinto de Miranda. Dados que, por seu turno,

12 IANTT, Habilitação do Santo Ofício, maço 136, doc. 2.257, fl. 1.

13 IANTT, Habilitação do Santo Ofício, maço 136, doc. 2.257, fl. 3.

14 IANTT, Habilitação do Santo Oficio, maço 136, doc. 2.257, fl. 52. 
consubstanciam o seu perfil de projeção como homem de negócios do Império português. Na década de 1750 , o capitão Antônio já era destacado comerciante no Rio de Janeiro e, como um bom empreendedor, no correr de sua trajetória buscou a diversificação de suas atividades e seus investimentos. Um dado pertinente para ilustrar essa questão, por exemplo, foi o vultoso empréstimo de Rs 6:000\$000 que fez para a Santa Casa da Misericórdia em 1752, que, além do mais, expressa o poder aquisitivo e o capital movimentado pelas suas atividades (Pesavento, 2009, p. 146).

A prosperidade econômica também permitiu a esse homem de negócios a aplicação de seu capital em propriedades, como a aquisição de uma chácara em Gamboa, na região sul da cidade do Rio de Janeiro, pelo preço de Rs 1:000\$000 (Pesavento, 2009, p. 146). Nessa propriedade, Antônio e Baltazar estabeleceram uma fábrica de curtumes, chamada Fábrica da Gamboa, que utilizava a casca do mangue para o processo de curtição ${ }^{15}$. Santos, por sua vez, destacou o fato de que naquele tempo o homem de negócios Manoel Luís Vieira intentou a montagem de uma fábrica concorrente em Paranaguá, mas Baltazar, que já gozava de influência na corte imperial, impediu-o de ir adiante com o negócio, alegando não haver mangue suficiente para mais de uma fábrica (Santos, 1994, p. 157).

Antônio e Baltazar eram proprietários de barcos e possuíam uma extração de cal. Em julho de 1757, Antônio cogitou a possibilidade de estabelecer um armazém de pólvora no Rio de Janeiro, mas foi logo embargado pela Ordem Terceira, que já havia reclamado esse privilégio (Santos, 1994, p. 157). De meados do decênio de 1750 em diante, as fontes documentais revelam uma crescente diversificação dos negócios de Antônio.As atividades passaram, então, a se espraiar por setores econômicos como as sociedades para o estabelecimento de fábricas, mas especialmente o exercício de cargos administrativos que exigiam o largo conhecimento em escrituração mercantil. Essa diversificação demonstra, ademais, a dinamização do Rio de Janeiro que à época estava se consolidando como importante entreposto do Império português na América Portuguesa. Uma dinâmica fundamentada em atividades econômicas diversificadas, como porto e

15 Os irmãos Pinto de Miranda, para o carregamento do mangue, possuíam barcos em Guaratiba, Santos e em outros lugares, além de um número considerável de escravos (Santos, 1994, p. 157). 
entreposto de abastecimento, assim como a iniciativa de fazer da praça um centro administrativo com a criação de instituições e a sua elevação a capital em 1763 (Guimarães; Pesavento, 2013).

$\mathrm{Na}$ senda das informações que imprimem relevância à lide mercantil de Antônio Pinto de Miranda, estavam as procurações registradas em cartório no Rio de Janeiro, como procurador de importantes homens de negócios de Portugal e de estrangeiros durante as décadas de 1750 e 1760. O levantamento realizado por Fábio Pesavento apurou que até 1760 Antônio acumulava cerca de dez nomeações como procurador para a realização de diversas atividades no Rio de Janeiro de outorgantes estrangeiros, como os hamburgueses Guilherme Thomsem \& Gaspar Crochman, o homem de negócios lisboeta Manoel Rodrigues Pontes, cavalheiro da Ordem de Cristo, Ignácio Pedro Quintela, representante da opulenta casa portuguesa dos Quintela e dos contratadores do tabaco, bem como seu irmão Baltazar Pinto de Miranda, que na altura era deputado da Junta de Comércio do Reino (Pesavento, 2009, p. 146). Assim também, foi procurador dos negociantes italianos Félix Recco, em 1765, e João Francisco Caparoni, em 1771 (Pesavento, 2009, p. 117, 118). Os dados igualmente não deixam dúvida do bom relacionamento entretecido por Antônio com negociantes estrangeiros e da praça mercantil de Lisboa.

A magnitude dos negócios de Antônio Pinto de Miranda, bem como a capacidade que a ele era conferida por sua habilidade com a escrituração mercantil, foram, certamente, atributos contumazes para que em novembro de 1756 fosse nomeado procurador do Cabido da Casa da Moeda do Rio de Janeiro (Pesavento, 2009, p. 146). Mais ainda, nesse mesmo ano Antônio foi nomeado como administrador da Companhia Geral de Agricultura das Vinhas do Alto Douro, para o Rio de Janeiro; uma função que preconizou a força econômica e a distinção social dos irmãos Pinto de Miranda como homens de negócios do Império português. A companhia, criada pelo então Conde de Oeiras, posteriormente Marquês de Pombal, Sebastião José de Carvalho e Melo, visava ao comércio e ao fomento rápido da região duriense, beneficiando toda a região Norte de Portuga ${ }^{16}$.

16 Para Jorge Borges de Macedo, em seu estudo sobre a situação econômica no tempo de Pombal," "a criação da Companhia de privilégio para os vinhos do Alto Douro foi o único meio a que puderam lançar mão os produtores da região vinícola do Alto Douro para proteger o seu valor econômico, abalado pela concorrência dos novos 
Com a instituição da companhia, cujos acionistas eram importantes figuras não só do Norte de Portugal, mas de todo o país, era necessário nomear os seus administradores, inclusive no Brasil (Monteiro, 2008). Estes eram escolhidos dentre os mais destacados comerciantes locais, que, por sua vez, deviam contar com um largo conhecimento sobre a escrituração em partidas dobradas. Nessa medida, Antônio beneficiou-se da influência de seu irmão Baltazar, que já residia em Lisboa e figurava como acionista dessa companhia, possuindo dez ações em seu nome, para assumir a função no Rio de Janeiro ${ }^{17}$. Segundo Santos, Baltazar escreveu para a Junta da Companhia no Porto, recomendando o seu irmão Antônio e o primo Luiz Antônio como administradores no Rio de Janeiro, obtendo resposta positiva em outubro de 1756, com a nomeação de ambos para o desempenho da aludida função (Santos, 1994, p. 155).

A partir de então, Antônio Pinto de Miranda irá fortalecer cada vez mais a sua competência e o potencial de suas atividades como homem de negócios do Império português, amealhando títulos e funções que lhe conferiam elevada distinção social. Um desses casos ocorreu em 1760, ao assumir o papel de administrador do Contrato das jeribitas para o seu arrematador Francisco José da Fonseca, homem de negócios da praça mercantil de Lisboa (Pesavento, 2009, p. 148). Nesse mesmo ano,

vinhos das novas regiões produtoras criadas pelo desenvolvimento da produção vinícola que o Tratado provocou, juntamente com o largo consumo das colônias. A Companhia dos Vinhos é a continuação e correcção do Tratado de Methwen, correspondendo, por assim dizer, no mercado interno àquilo que o Tratado de $\mathrm{Me}$ thwen foi no mercado externo: tentativa de eliminação de concorrentes ao vinho do Porto" (Macedo, 1989, p. 72). Nesse mesmo sentido, Nuno Gonçalo Monteiro apresenta a sua avaliação afirmando que, "de acordo com as propostas do dominicano Frei João Mansilha e com o apoio de grandes proprietários da região, como Luís Beleza de Andrade, seu primeiro provedor, foi criada, por alvará de 10 de Setembro de 1756, a Companhia Geral da Agricultura das Vinhas do Alto Douro, com o principal objectivo de 'sustentar com reputação dos vinhos a cultura das vinhas, e beneficiar ao mesmo tempo o Comércio, que se faz neste gênero, estabelecendo para ele um preço regular, de que resulte competente conveniência aos que o fabricam, e respectivo lucro aos que nele negociam'. A fim de proteger a qualidade dos vinhos e os preços, criou-se também a primeira região demarcada do mundo, circunscrevendo-se as propriedades que podiam produzir vinhos de primeira ordem para exportação" (Monteiro, 2008, p. 120-121).

17 Conforme o quadro apresentado por Fernando de Sousa, com a relação dos acionistas da companhia, Baltazar possuía dez ações (Sousa, 2006, p. 64). 
como já mencionado, terá a sua tão almejada aprovação como familiar do Santo Ofício.

O percurso ascendente de Antônio Pinto de Miranda prossegue em 1764, ao ser nomeado capitão da companhia de moedeiros da praça do Rio de Janeiro ${ }^{18}$. No mês de janeiro de 1765 , por meio de uma concessão régia, foi agraciado com uma sesmaria para estabelecimento de uma fazenda para criar gado vacum e animais no sertão do rio Paraíba, concedida pelas benfeitorias que estava disposto a realizar na mesma localização, como a construção de pontes e caminhos na barra do rio Piraí, freguesia de São Marcos ${ }^{19}$. Em 1767, Antônio assumiu o cargo de administrador da Dízima da Alfândega do Rio de Janeiro, um dos mais importantes contratos régios daquela capitania, atestando, mais uma vez, a competência e o conhecimento sobre a escrituração mercantil ${ }^{20}$.

No intuito de contornar as dificuldades econômicas já fundamentadas na crise do ouro de Minas Gerais, em 1765,Antônio Pinto de Miranda deu início ao projeto de constituição de uma fábrica de descasque de arroz na cidade do Rio de Janeiro. A expectativa depositada nesse negócio era pretensiosa, pois esperava que a cultura do arroz, em poucos anos, pudesse suprir o consumo desse gênero em Portugal. Desse negócio, há apenas a informação de que conseguiu, de fato, uma autorização régia para o funcionamento da fábrica ${ }^{21}$ (Santos, 1994, p. 158).

De outra parte, os anos dedicados ao comércio acrescidos de sua aptidão para o exercício administrativo fizeram de Antônio Pinto de Miranda um profissional disputado. Por possuir qualidades técnicas para o bom desempenho em cargos administrativos que exigiam o conhecimento sobre a contabilidade dobrada, em 1765 recebeu o convite para assumir a administração do Contrato das Baleias, com sede no Rio de Janeiro, liderado por Francisco José da Fonseca e pelo capitão Baltazar dos Reis. Seria, então, mais um importante cargo a ser desempenhado por ele;

18 AHU, Avulsos Rio de Janeiro, cx. 71, doc. 6.487.

19 AHU, Avulsos Rio de Janeiro, cx. 73, doc. 6.669.

20 AHU, Avulsos Rio de Janeiro, cx. 75, doc. 6.817.

21 Segundo Santos, tentativas e relatos de Antônio demonstram a dificuldade atravessada pela burguesia mercantil pombalina da década de 1760. Assim, "Pinto de Miranda ilustra bem o que pensava uma parte importante da sociedade portuguesa, quais os princípios por que se norteava, quais os seus valores fundamentais, quais os seus comportamentos" (Santos, 1994, p. 158). 
porém, viu-se obrigado a recusá-lo apresentando como justificativa o excesso de trabalho, mas colocando-se à disposição para supervisionar a empresa (Santos, 1994, p. 151).

Quatro anos mais tarde, em 1769, o substancioso comércio para o abastecimento das zonas de mineração já dava sinais de esgotamento e afetava de forma direta os homens de negócios como os da praça mercantil do Rio de Janeiro, que tinham boa parte de suas atividades voltadas para o comércio da região. Antônio Pinto de Miranda, na tentativa de reanimar os negócios de sua casa e aproveitando as oportunidades advindas de medidas políticas do Estado português para a diversificação da economia do Rio de Janeiro, firmará uma sociedade com Manoel Luís Vieira, Domingos Lopes Loureiro, Antônio de Oliveira Durão e Francisco Pinheiro Guimarães para o estabelecimento de uma fábrica de linho cânhamo (Pesavento, 2009, p. 148).

Para Nuno Gonçalo Monteiro, a crise econômica que afetou todo o Império português alcançou contornos inquestionáveis na década de 1760. Em sua análise, as circunstâncias excepcionais de guerra acrescidas de aperturas financeiras, vinculadas à crise mineratória, entre outros, foram os motivos que colocaram em evidência essa crise. Assim, a segunda fase do governo pombalino, principiada em 1759, já era uma época de crise, com consequências desastrosas para os fundos do Estado, para a produção e para o comércio ${ }^{22}$ (Monteiro, 2008).

No entanto, o quadro pintado por Nuno Monteiro pode ser matizado, especialmente ao se observar algumas medidas políticas assumidas pelo Marquês de Pombal para contornar esse contexto de crise. Guimarães e Pesavento, por exemplo, avaliam positivamente a política pombalina de nomear D. Luís de Almeida Portugal e Mascarenhas, 2ำ Marquês do Lavradio, como vice-rei da América Portuguesa (1770). A atuação de Lavradio foi frutífera na medida em que estabeleceu estratégias para o fortalecimento da economia do Rio de Janeiro, vislumbrando-o como um locus privilegiado da dinâmica colonial brasileira. Dentre as medidas de Lavradio, estavam o aumento do controle da movimentação portuá-

22 De suas postulações, ressaltamos ainda:"Mas se a quebra do comércio luso-britânico e das remessas e amoedação do ouro do Brasil é indiscutível, pode questionar-se se a crise não correspondeu, afinal, a uma viragem, a qual acabou por favorecer alguns dos desígnios intencionalmente procurados pelo valido de D. José" (Monteiro, 2008, p. 214). 
ria com ajustes dos direitos sobre produtos, a elevação das receitas ao incentivar a implementação de novas culturas (arroz, anil, cochonilha, linho cânhamo etc.), o combate ao contrabando e o reajuste das despesas (inclusive construindo uma nova Alfândega), entre outras (Guimarães; Pesavento, 2013).

Assim, é possível vislumbrar as estratégias de Antônio Pinto de Miranda como resultado de crise econômica, mas também de estímulos que se inserem na conjuntura por que passava o Império português da segunda metade do século XVIII. Ilustrativas desse cenário são as observações de Eugênio dos Santos sobre os negócios de Antônio Pinto de Miranda, referindo-se ao constante e estreito contato que ele manteve com homens influentes da sociedade daquele tempo, como o frei João de Mansilha e Francisco Xavier de Mendonça Furtado, ambos vinculados ao círculo de convívio do Marquês de Pombal, sendo o último seu irmão (Santos, 1994, p. 157).

Onze anos se passaram desde que havia se tornado um familiar do Santo Ofício, quando em julho de 1771, aos 59 anos de idade, Antônio Pinto de Miranda resolveu pleitear o cobiçado título de cavaleiro da Ordem de Cristo. Na altura, contava com uma trajetória mercantil bem-sucedida e a sua desenvoltura para lidar com a escrituração mercantil permitiu-lhe o desempenho de importantes cargos e funções, como o posto de capitão da companhia dos moedeiros da praça do Rio de Janeiro, de secretário da Ordem Terceira de São Francisco e de provedor da Confraria de Nossa Senhora da Candelária.

Mas foi o cargo de administrador no Rio de Janeiro da Companhia dos Vinhos de Alto Douro que projetou sua carreira mercantil para um patamar mais elevado, seguido ainda, naquele mesmo ano, da administração do contrato da Dízima da Alfândega do Rio de Janeiro. Contando com esse amplo e favorável histórico, Antônio deu entrada ao processo de habilitação da sua mercê, que foi obtida mediante a renúncia de seu irmão Baltazar, apresentando-se como um homem de negócios e irmão do cavaleiro Baltazar Pinto de Miranda, concorrendo com as qualidades necessárias para professar na aludida Ordem Militar ${ }^{23}$.

Foi então, com "20 e tantos anos", que Antônio chegou à cidade do Rio de Janeiro em companhia do irmão mais novo, Baltazar Pinto de

23 IANTT, Habilitação da Ordem de Cristo, letra A, maço 29, doc. 2. 
Miranda, e "naquelas partes do Brasil é rico e muito abastado de bens temporais" 24 . Os relatos, de modo geral, eximiam-no de qualquer ligação com o universo mecânico, sendo seus pais também reputados como honrados lavradores, vivendo do rendimento das suas fazendas, e, da mesma forma, "seus avós paternos e maternos, que igualmente se sustentaram dos bens próprios que tinha e suposto neles trabalhavam, nunca o faziam nos alheios por jornal nem conveniência, nem algum deles serviu emprego, ou oficio vil ou mecânico" 25 . Esses testemunhos trazem fragmentos de uma qualidade social sustentada pela família dos Luízes que viviam nos lugarejos de Santa Marinha do Zêzere, ao longo de algumas gerações. Uma condição sine qua non para o sucesso das trajetórias daqueles que adentraram no universo dos negócios mercantis e fizeram carreira no ultramar, como o nosso personagem Antônio Pinto de Miranda.

Entretanto, os deputados da Mesa de Consciência e Ordens, tendo em vista que Antônio já contava com mais de 50 anos, ou seja, a idade máxima para o ingresso na cavalaria da Ordem de Cristo, julgaram-no impedido de receber a provisão da sua mercê. Mas, como de costume, Antônio Pinto de Miranda recorreu da sentença em uma nova petição, na qual se valeu da renúncia feita por Baltazar Pinto de Miranda a seu favor, concedida pelos longos anos de serviço como contador-geral do Real Erário. A proeminência do cargo ocupado por seu irmão era indubitável e, portanto, o seu pedido de reconsideração obteve o efeito desejado.Assim, em 1772, os membros da Mesa deliberavam pela dispensa do impedimento, aprovando a habilitação da mercê do postulante ${ }^{26}$.

O ingresso na cavalaria da Ordem de Cristo, certamente o mais cobiçado título de distinção social para um homem de negócios, encerrava a busca de Antônio Pinto de Miranda pelo reconhecimento social de sua projeção econômica no decurso de pouco mais de três décadas de ativa atuação no ramo mercantil. Por ser considerado um dos títulos de mais elevada nobreza pelos negociantes do Império português à época, os postulantes à insígnia buscavam se municiar de um amplo histórico de feitos a favor da Coroa, a fim de recebê-lo. Assim, a sua obtenção enter-

24 IANTT, Habilitação da Ordem de Cristo, letra A, maço 29, doc. 2, fl. 9v.

25 IANTT, Habilitação da Ordem de Cristo, letra A, maço 29, doc. 2, fl. 9v.

26 IANTT, Habilitação da Ordem de Cristo, letra A, maço 29, doc. 2, fl. 9v. 
rava, de vez, qualquer resquício que pudesse pôr dúvida à qualidade e nobreza dos agraciados com o título, um signo indelével de sucesso na sociedade colonial e no universo dos homens de negócios do Império luso.

A última fonte de que dispomos sobre Antônio Pinto de Miranda é, de fato, o seu processo para habilitação da Ordem de Cristo. A dificuldade em perscrutar seus últimos anos de vida conjugada à crise gerada pela diminuição das atividades minerais da América Portuguesa, explicitamente assinalada em suas correspondências, leva a crer que a assertiva de Eugênio dos Santos sobre a sua fuga para a capitania de Minas Gerais, em junho de 1773, é uma possibilidade que não se deve descurar (Santos, 1994, p. 159).

\section{A trajetória de Baltazar Pinto de Miranda}

Em 1755, o minhoto Baltazar Pinto de Miranda já havia realizado o caminho de volta da América Portuguesa para a metrópole, de onde passou a responder pelos negócios que manteve com seu irmão Antônio Pinto de Miranda, a partir da praça mercantil de Lisboa. A história de vida de Antônio, analisada na seção anterior, descortinou elementos contundentes sobre o percurso trilhado por ele e por seu irmão Baltazar, como negociantes que ascenderam economicamente depois de alguns anos de atuação no comércio de abastecimento das zonas de mineração. Uma ascensão acompanhada pela diversificação de suas atividades e igualmente projetada para o âmbito social, com a aquisição de títulos de nobiliarquia, importantes cargos administrativos e a participação em instituições religiosas de prestígio, como as irmandades, o Santo Ofício e a Ordem de Cristo.

A carreira mercantil de Baltazar começou bem cedo, segundo afirmaram algumas testemunhas de Santa Marinha do Zêzere para seu processo de habilitação para a Ordem de Cristo, iniciado em $1759^{27}$. Quando ainda muito jovem, aproximadamente aos 13 anos de idade, saiu de casa levado pelo irmão Antônio Pinto de Miranda, que na época era caixeiro do negociante hamburguês Diogo Berquenhout na cidade do Porto. De

\footnotetext{
27 IANTT, Habilitação da Ordem de Cristo, letra B, maço 3, doc. 15.
} 
lá, em 1739, ambos partiram rumo ao Rio de Janeiro, onde estabeleceram uma casa comercial voltada, sobretudo, para o mercado de abastecimento dos núcleos mineratórios.

Em Santa Marinha do Zêzere, as testemunhas afirmavam que Baltazar possuía a qualidade necessária para se tornar um cavaleiro da Ordem Cristo. A devassa em sua vida pregressa jogava luz à vida honrada que levavam seus avós e pais, como lavradores, sendo também o pai carpinteiro e tanoeiro de pipas, mestre de meninos e escrivão do Jú́zo de Órfãos do concelho de Baião ${ }^{28}$.

Também foram colhidos depoimentos de testemunhas em Lisboa, onde morava o postulante na época de sua habilitação. Dentre elas, estava o homem de negócios João Álvares Chaves, que recordava a vida de Baltazar no Rio de Janeiro, quando "assistia" na loja do seu irmão Antônio vendendo em grosso as "fazendas secas de pano de linho, baetas, chapéus e ferragens". Disse também que algum tempo depois retornava do Brasil, estabelecendo uma "loja de mercearia e papel na rua Nova dos Ferros", em Lisboa, em cuja loja "nunca assistira", mas apenas o seu sócio, "e tratara como atualmente faz em todo o gênero de negócio, e enviar fazendas para o Brasil"29.

Num outro depoimento que igualmente relatava a trajetória mercantil de Baltazar, a testemunha certificava que no Rio de Janeiro ele servia na loja do seu irmão, exercendo as incumbências do seu negócio e de "ir as Minas fazer algumas cobranças respectivas ao dito seu irmão". $\mathrm{Na}$ corte, desde o início, "sendo já homem de negócio, com sociedade no Rio de Janeiro continuava em enviar carregações para as partes do Brasil". Passando a servir, algum tempo depois, como deputado da Junta Geral do Comércio, mas ainda "negociando em todos os ramos do comércio, que se lhe oferecem em grosso, vivendo com tratamento a lei da nobreza ${ }^{30}$.

Mesmo se valendo da renúncia da mercê de Antônio Carlos Bravo, Baltazar Pinto de Miranda seguramente desfrutou dos beneficios concedidos por servir como deputado da Junta Geral do Comércio, pela

28 IANTT, Habilitação da Ordem de Cristo, letra B, maço 3, doc. 15, fl. 6.

29 IANTT, Habilitação da Ordem de Cristo, letra B, maço 3, doc. 15, fl. 7.

30 IANTT, Habilitação da Ordem de Cristo, letra B, maço 3, doc. 15, fl. 6v. 
praça do Porto, "dos primeiros da criação dela" 31 . Uma função que poderia eximir aqueles que serviam à Coroa em cargos relevantes - como era aquele ocupado por ele - das devassas para habilitação na Ordem de Cristo $^{32}$. Dessa forma, em maio de 1760, a Mesa de Consciência e Ordens aprovava a mercê de Baltazar, que então vivia em Lisboa na rua Nova de São Bento e freguesia de Santa Izabel.

Ao analisar os copiadores e correspondências de Antônio Pinto de Miranda, Eugênio dos Santos pôde observar que Baltazar Pinto de Miranda foi um próspero homem de negócios atuante na praça mercantil de Lisboa. As fontes analisadas por ele também dão conta de que estava na capital do Império português, quando ocorreu o terremoto de 1 o de novembro de 1755, e de que seus negócios foram fortemente afetados pelo sismo, mas não aniquilados. Apesar do infortúnio, aos poucos, Baltazar recompôs suas atividades (Santos, 1994, p. 157).

Um acontecimento relevante no ensejo de recuperação de seus negócios foi, de certo, o ingresso como deputado da Junta de Comércio dos Reinos pela praça mercantil do Porto, criada em 1756 pelo primeiro-ministro de D. José, Sebastião José de Carvalho e Melo. O acesso e a permanência nessa instituição mercantil fundamentam a desenvoltura e o bom relacionamento mantidos por Baltazar, ao longo dos anos, com a administração portuguesa, reforçados com o seu engajamento em outras instituições, como, por exemplo, o fato de ter se tornado um acionista da Companhia Geral dos Vinhos do Alto Douro, possuindo dez ações ${ }^{33}$.

31 A mercê de Baltazar foi concedida pela renúncia que fez Antônio Carlos Bravo a seu favor. IANTT, Registro Geral de Mercês, reinado de D. José I, livro 13, fl. 498.

De acordo com Jorge Pedreira, "privilégios semelhantes aos que se atribuíram aos acionistas e diretores da Companhia do Grão Pará - e que depois se alargaram aos das outras companhias privilegiadas - foram conferidos pelos Estatutos da Junta do Comércio aos cargos de provedor, secretário e deputados da Junta, cujos primeiros titulares seriam agraciados, por inerência, com o hábito de cavaleiros de Cristo" (Pedreira, 1995, p. 87).

33 Segundo Francisco Falcon, o caráter monopolístico da política mercantilista endossada por Sebastião José de Carvalho e Melo era de fortalecer os instrumentos legais às organizações, como a Junta do Comércio e as companhias mercantis, que, além do mais, compunham-se de representantes do abastado círculo mercantil estreitamente associado ao aparelho de Estado. Na esfera social, ocorreu, outrossim, a promoção desse grupo mediante a concessão de cargos públicos de distinção e insígnias nobilitantes, como o ingresso nas ordens militares, especialmente a de Cristo (ver Falcon, 1993, p. 409). 
Além das informações dispostas no processo de habilitação para a Ordem de Cristo, que trazem evidências qualitativas para a composição da trajetória mercantil de Baltazar Pinto de Miranda, existe a notícia de que em 1760 esteve no Rio de Janeiro, enviado pela Junta do Comércio do Porto, aproveitando a oportunidade para a cobrança de algumas dívidas particulares e regressando para Lisboa no ano seguinte (Santos, 1994, p. 157). Em 1762, já era considerado agente de maior trato no patamar dos homens de negócios do Império português, mas essa condição foi, mais uma vez, reiterada pela nomeação para o cargo de contador-geral da Fazenda das províncias do reino e ilhas dos Açores, com um ordenado anual de Rs $40 \$ 000^{34}$.

Avançando duas décadas depois, em 1791, perscrutamos uma última fonte documental alusiva a Baltazar Pinto de Miranda: o seu inventário post mortem. Falecido em 1791, era viúvo de D. Thereza Marcelina de Castro e estava casado, pela segunda vez, com D. Florinda Thereza de Santa Anna Pinto, responsável pela inventariação do seu espólio ${ }^{35}$. Além de sua segunda esposa, Baltazar possuía mais dois herdeiros, seus filhos Baltazar José de Miranda e Castro, que morava na Índia, fruto de seu primeiro casamento, e João Pinto de Miranda, do seu segundo casamento, que tinha de 6 para 7 anos de idade quando seu pai faleceu. A composição do patrimônio de Baltazar revela que, embora tenha se tornado um ilustre negociante da praça mercantil de Lisboa, especialmente durante os anos de governação pombalina, o seu espólio era relativamente modesto pela expressividade dos negócios e atividades que certamente desenvolveu no decurso de uma trajetória mercantil bem-sucedida, alcançando um montante final líquido de Rs 14:067\$638 .

Na década de 1760, uma primeira avaliação do seu patrimônio foi realizada mediante a feitura do inventário dos bens de sua falecida esposa, D.Thereza Marcelina de Castro, alcançando um monte líquido de

34 Para Fernando Dores da Costa, os negociantes constituíram um grupo sensível à obtenção de distinções e à indicação de funções administrativas, uma vez que, por meio delas, materializavam a ascensão social. Assim, "para os negociantes de grosso trato o problema não é a sua nobilitação, mas a progressão na hierarquia da nobreza. Procuram assinalar que não pertencem à mais baixa escala (à massa dos nobres simples ou razos), mas que situam em níveis superiores" (Costa, 1992, p. 446).

35 Feitos Findos, Inventário orfanológico, B, maço 52, n. 7.

36 Feitos Findos, Inventário orfanológico, B, maço 52, n. 7, fls. 3v, 4. 
Rs 27:603\$626, conforme declarou D. Florinda; quase duas vezes o valor calculado em $1791^{37}$. A comparação do montante desses dois espólios nos faz deduzir que os investimentos de Baltazar declinaram no correr de duas décadas. Sendo, ademais, o monte líquido do inventário de sua primeira esposa uma quantia módica pela expressividade dos negócios de Baltazar Pinto de Miranda no decênio de 1750. Valor que pode ser corroborado pelas perdas ocasionadas com o terremoto de 1755, mas também, em parte, elucidado a partir da declaração de D. Florinda, cujo teor informava a impossibilidade de se liquidar as legítimas maternas porque "se viu fazer balanço as grandes perdas que tinha tido" 38 .

A prevalência de um patrimônio fortemente empenhado nos negócios e dívidas ativas era uma realidade comumente estendida à maioria dos homens de negócios do Império português do Setecentos, e influiu diretamente nos valores da composição patrimonial desses agentes. Nesse contexto, os dados figurados na presente pesquisa corroboram o resultado apresentado pela análise prosopográfica de Jorge Pedreira, em seu estudo sobre os homens de negócios da praça mercantil de Lisboa. Ou seja, as dívidas ativas perfizeram o principal componente das fortunas dos negociantes, enquanto os recursos patrimoniais aplicados em bens de raiz alcançavam apenas 15\% de suas fortunas (ver Pedreira, 1995, p. 308).

Baltazar Pinto de Miranda, ao longo de sua bem-sucedida carreira mercantil, protagonizou a seu favor um processo de mobilidade social ascendente, conquistando postos relevantes na esfera administrativa da metrópole portuguesa. Assim, ao falecer, acumulava ordenados pelo exercício das funções de contador-geral do Real Erário, diretor dos diamantes e por expediente na extinta Procuradoria das Reais Cavalarias ${ }^{39}$.

A casa em que residia com sua esposa, D. Florinda, e seu filho, João Pinto de Miranda, certamente era uma nobre vivenda situada no largo

37 Segundo Eugênio dos Santos, Antônio Pinto de Miranda, em 1765, mandou celebrar missas pela alma de seu irmão João Pinto de Miranda e sua cunhada D. Thereza Marcelina, o que nos faz supor que ela teria falecido ainda na primeira metade da década de 1760. Nessa medida, o montante líquido do patrimônio alcançado pelo seu inventário post mortem referiu-se, seguramente, ao patrimônio constituído no auge da atuação de Baltazar Pinto de Miranda como homem de negócios (ver Santos, 1994).

38 Feitos Findos, Inventário orfanológico, B, maço 52, n. 7, fl. 145v.

39 Feitos Findos, Inventário orfanológico, B, maço 52, n. 7, fl. 113. 
do Carmo, no bairro Alto, uma propriedade alugada que pertenceu ao Marquês de Pombal. A família viveu com pompa e luxo. A avultada relação de itens a compor os móveis, ornatos, louças e enxovais não deixa dúvida de que a residência era guarnecida de peças que imprimiam um estilo de vida do mais elevado padrão de luxo e conforto à época.

A avaliação do recheio da casa, do vestuário e das joias alcançou a quantia de Rs 2:963\$850 distribuídos entre o móvel da casa (Rs 923\$820), uma sege com dois machos (Rs $375 \$ 200$ ), a biblioteca (Rs 485\$470) e os itens de ouro, prata e pedras preciosas (Rs 1:179\$360) ${ }^{40}$. A mobília da casa, por seu turno, era composta por diversas mesas e cadeiras, simples ou com adornos, catres, estantes, guarda-roupa, relógio e espelhos fabricados com madeiras nobres, como o jacarandá, a nogueira e o vinhático, além de madeiras do Brasil. O vasto número de utensílios de prata, como bandejas, salvas, talheres, pratos de mesa, fruteiras, acrescido de louças da Índia e dos artefatos de cobre, com tudo o mais que pudesse compor as mais suntuosas cozinhas e os utensílios de mesa, revelam o alto padrão de vida da família.

De igual modo, Baltazar Pinto de Miranda era possuidor de uma magnífica biblioteca, formada por aproximadamente 508 títulos, dentre os quais vários possuíam mais de um volume. A diversidade de temas literários e as mais variadas áreas de conhecimento das obras arroladas em sua biblioteca conferem a esse homem de negócios um elevado nível intelectual e interesse pelo conhecimento sobre os mais diversos temas. Somente uma enciclopédia, composta por 33 volumes, foi avaliada em Rs $86 \$ 400$. Entre os títulos havia importantes obras voltadas para o universo mercantil, como o Dictionnaire economique, com 4 volumes, e o Dictionnaire universel de commerce, com 5 volumes. Um exemplar do Comércio das colônias inglesas, outro do Manual des negociants e 39 volumes do Journal Économique revelavam que Baltazar se colocava a par das discussões e dos conhecimentos disseminados na esfera mercantil europeia. Contava também sua biblioteca com um exemplar da famosa obra História da América, de Sebastião da Rocha Pita, o Vocabulário portuguez e latino, de Bluteau, os estatutos (antigos e modernos) da Universidade de Coimbra, um Dom Quixote, de Miguel de Cervantes, e o clássico $A$ arte de furtar. De outra parte, vastas foram as obras voltadas para os temas

40 Feitos Findos, Inventário orfanológico, B, maço 52, n. 7, fls. 150, 150v, 151. 
religiosos, como os títulos que narravam a história de vida dos santos e as obras de devoção ${ }^{41}$.

Entretanto, o que mais impressiona entre os bens arrolados nesse inventário são as peças de ouro, prata e pedras preciosas. Dentre esses bens que imprimiam ostentação e elevada distinção social a Baltazar Pinto de Miranda nas ocasiões festivas e nos compromissos importantes, estava um luxuoso hábito de Cristo, que era, por sinal, a sua mais valiosa joia. Tratava-se, pois, de um hábito para o peito com passagem de fita larga, composto por uma cruz lisa arrematada por folhas e botões, levando por cima uma flor maior de ouro, um botão com " 55 diamantes brilhantes, seis na flor em cima, maiores, com praça de dois até três grãos e os mais de vários tamanhos cravados em prata a Alma de hábito com 20 diamantes brilhantes, alguns rosas virados a cruz com 32 granadas inglesas cravadas em ouro", avaliado em Rs $264 \$ 000^{42}$. Além deste, foram descritos outros cinco hábitos, de menor valor e preciosidade.

As suas roupas, por seu turno, acompanhavam o nobre estilo de vida que levava na corte do Império português, compostas por véstias de tecidos nobres como os de seda, de tafetá e de gorgorão. Nesse segmento, as vestimentas religiosas ocuparam certa expressividade, possuindo uma capa da Irmandade dos Passos, de gorgorão, um hábito da Ordem Terceira de Nossa Senhora do Carmo e um balandrau de seda da Irmandade da Misericórdia ${ }^{43}$.

Em se tratando de bens de raiz, o espólio de Baltazar Pinto de Miranda relacionou apenas uma propriedade chamada Quinta da Apelação, que ficava no lugar de mesmo nome e que foi o bem avaliado em mais alta conta, alcançando o valor de Rs 4:081 $\$ 320^{44}$. A propriedade era composta por um primeiro conjunto de 7 casas, possuindo tanque de pedra, adega, cavalariça, palheiro e, por fora, mais 1 casa pequena. Além destas, havia um pavimento de sobrado com 11 casas "com alguma nobreza”, com um pátio e água-furtada, tudo bem construído. A quinta possuía um extenso vinhedo com 212 pilares de pedra, árvores de frutas, pomar de espinho, olival, terras para a semeadura e um poço com tanque

\footnotetext{
41 Feitos Findos, Inventário orfanológico, B, maço 52, n. 7, fls. 57-112.

42 Feitos Findos, Inventário orfanológico, B, maço 52, n. 7, fls. 6, 6v.

43 Feitos Findos, Inventário orfanológico, B, maço 52, n. 7, fls. 9, 9v.

44 Feitos Findos, Inventário orfanológico, B, maço 52, n. 7, fl. 119v.
} 
e canos de regar. O imóvel era arrendado para a Sereníssima Casa de Bragança ${ }^{45}$.

Depois de três meses do falecimento de Baltazar Pinto de Miranda, a parte do seu inventário post mortem alusiva aos bens móveis e imóveis do casal estava concluída. Porém, o curto prazo concedido para a finalização completa desse espólio compeliu a inventariante e viúva, D. Florinda, a apresentar uma petição à rainha D. Maria I, solicitando a concessão de mais três anos para se findar por completo o inventário de seu marido. $\mathrm{O}$ motivo alegado era a impossibilidade de se proceder a um levantamento completo das dívidas ativas e passivas do casal enquanto não se fizesse o ajustamento das contas "com várias pessoas existentes nos Domínios Ultramarinos, com os quais o mesmo marido da suplicante, tinha contas muito consideráveis" ${ }^{36}$. Esse fato atesta, ademais, que o inventariado ainda possuía algum envolvimento com o universo mercantil nos últimos anos de vida.

O prazo concedido, no entanto, foi de apenas um ano e resultou numa apresentação parcial do rol das dívidas ativas que somaram a quantia de Rs 10:835\$597, um montante espraiado entre os diversos negócios que Baltazar possuía tanto na metrópole quanto nos domínios ultramarinos. Em outubro de 1792, foi elaborado o Termo de Encerramento e Formal de Partilha de seus bens inventariados. Com ele, determinavam-se as receitas para proceder à liquidação das dívidas passivas do casal e o repasse da legítima materna de Baltazar José de Miranda e Castro, filho que teve do seu primeiro matrimônio, no valor de Rs $645 \$ 798$. Do remanescente, restaria o montante líquido do patrimônio, dividido em duas partes iguais, uma para o pagamento da meação da viúva e inventariante, D. Florinda, e outra a ser dividia em partes iguais entre os dois filhos do inventariado. Por fim, o documento mencionou as dívidas que ao casal devia a herança de Manoel Cardoso Pinto e de Carlos Tristão de Castro, como ação de lembrança a fim de serem divididas quando liquidadas ${ }^{47}$.

Os abatimentos do monte bruto alcançaram a soma de Rs 4:841 $\$ 308$, distribuídos em diversos pagamentos aos seus devedores. Acresciam a esses valores as despesas com o advogado, o funeral, a celebração de missas,

45 Feitos Findos, Inventário orfanológico, B, maço 52, n. 7, fls. 118-119v.

46 Feitos Findos, Inventário orfanológico, B, maço 52, n. 7, fl. 120.

47 Feitos Findos, Inventário orfanológico, B, maço 52, n. 7, fls. 149v, 150. 
os médicos e o aluguel da casa em que moravam, entre outras. Após o pagamento das dívidas, o patrimônio líquido foi de Rs 14:067\$638, de cujo montante se repassaram à viúva, pela sua meação, Rs 7:033\$819. Os filhos, por sua vez, receberam de legítima paterna Rs 3:516\$909 cada $u^{48}$. Os herdeiros de Baltazar Pinto de Miranda também passaram a receber um benefício da Coroa pelos serviços que ele prestou na contadoria-geral do Real Erário, percebendo a remuneração de Rs $500 \$ 000$ anuais pagos pelo Real Erário, divididos entre sua viúva, D. Florinda, e os filhos Baltazar José Pinto de Miranda e João Pinto de Miranda ${ }^{49}$.

\section{Considerações finais}

A reconstituição, ao menos parcial, do universo econômico e social dos irmãos Pinto de Miranda consubstanciou uma análise profícua sobre a atuação de jovens portugueses que se serviram inicialmente do comércio de abastecimento das zonas de mineração da América Portuguesa e se tornaram destacados homens de negócios do Império luso. À luz dessas informações, apreendemos algumas das transformações ocorridas em um momento de transição política e econômica crucial para o Estado português, relacionadas ao processo de fortalecimento de sua burguesia mercantil com os novos ventos trazidos sob os auspícios da política pombalina, na segunda metade do século XVIII.

A pesquisa encetada corroborou, por assim dizer, com a literatura que versa sobre o fortalecimento da comunidade mercantil do Império português consubstanciado pela aludida política pombalina, durante o reinado de D. José. Mais ainda, mediante a trajetória de vida dos irmãos Pinto de Miranda, desvelamos nuanças e padrões da dinâmica em torno da elite mercantil portuguesa entre os últimos anos de governação joanina, estendendo-se até o reinado de D. Maria I.

Nessa medida, Antônio e Baltazar ascenderam economicamente em uma época marcada pelo substancioso comércio de abastecimento da região mineradora, os decênios de 1740 e 1750. Mas, assim como tantos outros negociantes à época, souberam muito bem construir em torno

48 Feitos Findos, Inventário orfanológico, B, maço 52, n. 7, fls. 166, 166v.

49 IANTT, Registro Geral de Mercês, reinado de D. Maria I, livro 27, fl. 16v. 
de suas atividades os vínculos necessários para a integração ao grupo de negociantes beneficiados pela Coroa portuguesa. Dentre eles, o engajamento em redes mercantis de fôlego e a diversificação de seus negócios, bem como a transformação de seu capital econômico em simbólico, com a aquisição de insígnias que imprimiam distinção social e o desempenho de funções administrativas associadas ao Estado que conferiam prestígio.

De outra parte, as histórias aqui descortinadas adentraram pelo reinado de D. Maria I e, por seu turno, também refletiram o período, cujo contexto econômico atravessado pelo Império português já não se encontrava em uma boa fase para o grupo mercantil que se beneficiou com o comércio vinculado às regiões mineratórias da América Portuguesa. Aliás, o decênio de 1760 apresentava indicadores de uma crise e nova situação econômica do Império, e consequentemente do seu setor mercantilista. As fontes documentais que permitiram a constituição das trajetórias dos irmãos Pinto de Miranda claramente nos dão conta dessa situação econômica atravessada pelo Império, assim como da dinâmica que se procurou estabelecer mediante o cenário que se configurava, especialmente em relação à América Portuguesa.

As trajetórias de Antônio e Baltazar descortinam estratégias importantes e comumente adotadas pelos homens de negócio do Império português para conferir poder econômico e distinção social ao grupo, como a diversificação das atividades mercantis, a participação em contratos régios, as funções em cargos administrativos e a aquisição de insígnias. No entanto, refletem igualmente tentativas de investimentos malsucedidos, correspondências lamuriosas e um patrimônio pouco avultado auferido ao longo de uma carreira mercantil bem-sucedida, que sinalizam para um novo cenário, menos favorável àqueles que se beneficiaram, outrora, do comércio alentado pela mineração. Por fim, ressaltamos que o referencial vislumbrado através dos percursos aqui reconstituídos, sugere que as experiências individuais, fundamentadas em análises micro-históricas, mormente oferecem expectativas enriquecedoras de contextualização e de análises trilhadas para a construção de uma abordagem macro-histórica.

\section{Referências bibliográficas}

AZEVEDO, João Lúcio de. O Marquês de Pombal e sua época. São Paulo:Alameda, 2004. 
COSTA, Fernando Dores da. Capitalistas e serviços: empréstimo, contratos e mercês no final do século XVIII. Análise Social, v. XXVII (116-117), p. 441-460, 1992.

COSTA, Leonor Freire. Império e grupos mercantis. Entre o Oriente e o Atlântico (século XVII). Lisboa: Livros Horizonte, 2002.

COSTA, Leonor Freire; ROCHA, Maria Manuela. Remessas de ouro brasileiro: organização mercantil e problemas de agência em meados do século XVIII. Análise Social. Lisboa, v. XLII (182), p. 77-98, 2007.

DONOVAN,William. Commercial enterprise and Luso-Brazilian society during the Brazilian gold rush: the mercantile house of Francisco Pinheiro and the Lisbon to Brazil trade, 1695-1750. Baltimore: Johns Hopkins University, 1990 (Doctoral Dissertation).

ELLIS, Miriam. Contribuição ao estudo do abastecimento das zonas mineradoras no século XVIII. Revista de História. São Paulo, v. 17, n. 36, p. 429-464, 1958.

ELLIS, Miriam. Comerciantes e contratadores no passado colonial. Revista do Instituto de Estudos Brasileiros. São Paulo, USP, n. 24, p. 97-122, 1982.

FALCON, Francisco J. C. A Época Pombalina: política econômica e Monarquia ilustrada. São Paulo: Ática, 1982.

GODINHO,Vitorino Magalhães. Portugal, as frotas do açúcar e as frotas do ouro (16701770). Revista de História. São Paulo, FFLCH-USP, ano IV (15), p. 69-88, jul.-set. 1953.

GUIMARÃES, Carlos Gabriel; PESAVENTO, Fábio. Contratos e contratadores do Atlântico Sul na segunda metade do Setecentos. História, Histórias. Brasília, v. 1, n. 1, 2013.

MACEDO, Jorge Borges de. Burguesia. Na época moderna. In: SERRÃO, Joel (dir.). Dicionário de história de Portugal.V. I. 2. ed. Porto: Arcádia, 1985.

MACEDO, Jorge Borges de. A situação econômica no tempo de Pombal. Lisboa: Gradiva, 1989.

MONTEIRO, Nuno Gonçalo. D. José. Lisboa:Temas e Debates, 2008.

OLIVAL, Maria Fernanda. As ordens militares e o Estado moderno. Honra, mercê e venalidade em Portugal (1641-1789). Lisboa: Estar, 2001.

PEDREIRA, Jorge Miguel Viana. Os homens de negócio da praça de Lisboa de Pombal ao Vintismo (1755-1822): diferenciação, reprodução e identificação de um grupo social. Lisboa: Universidade Nova de Lisboa, 1995 (Tese de Doutorado).

PEDREIRA, Jorge MiguelViana.Tratos e contratos: atividades, interesses e orientações dos investimentos dos negociantes da praça de Lisboa (1755-1822). Análise Social, v. XXXI (136-137), p. 355-379, 1996.

PEREIRA, Alexandra Maria. Das minas à corte, de caixeiro a contratador: Jorge Pinto de Azeredo. Atividade mercantil e negócios na primeira metade do século XVIII. São Paulo: Alameda, 2017.

PESAVENTO, Fábio. Um pouco antes da corte: a economia do Rio de Janeiro na segunda metade do Setecentos. Niterói: UFF, 2009 (Tese de Doutorado).

SANTOS, Eugênio dos. A Companhia Geral da Agricultura das Vinhas do Alto Douro e a dinamização do triângulo constituído por Portugal Continental, ilhas e Brasil 
no séc. XVIII: aspectos de uma investigação em curso. Boletim do Instituto Histórico da Ilha Terceira. Angra do Heroísmo, v. XLVIII, 1993 (Separata).

SANTOS, Eugênio dos. Relações da cidade e região do Porto com o Rio de Janeiro e Minas Gerais no século XVIII. ANAIS DO I COLÓQUIO DE ESTUDOS HISTÓRICOS BRASIL-PORTUGAL. Belo Horizonte: PUC-MG, 1994.

SILVA, Andrée Mansuy-Diniz. Une voie de connaissance pourl'histoire de la societé portugaise au XVIII e siècle: lês micro-biographies (sources - méthode - étude de cas). Clio - Revista de História da Universidade de Lisboa. Lisboa, n. 1, p. 21-65, 1979 (Separata).

SILVA, Maria Beatriz Nizza da. Ser nobre na colônia. São Paulo: Editora UNESP, 2005. 